\title{
Comparison of hot and cold spell effects on cardiovascular mortality in individual population groups in the Czech Republic
}

\author{
Jan Kyselý ${ }^{1,2, *}$, Eva Plavcová ${ }^{1,3}$, Hana Davídkovová ${ }^{1,4,5}$, Jan Kynčl ${ }^{6,7}$ \\ ${ }^{1}$ Institute of Atmospheric Physics, Prague, Czech Republic \\ ${ }^{2}$ Global Change Research Centre, Brno, Czech Republic \\ ${ }^{3}$ Faculty of Mathematics and Physics, Charles University, Prague, Czech Republic \\ ${ }^{4}$ Faculty of Science, Charles University, Prague, Czech Republic \\ ${ }^{5}$ Institute of Geophysics, Prague, Czech Republic \\ ${ }^{6}$ Centre for Epidemiology and Microbiology, National Institute of Public Health, Prague, Czech Republic \\ ${ }^{7}$ Third Faculty of Medicine, Charles University, Prague, Czech Republic
}

\begin{abstract}
We compared the effects of hot and cold spells on cardiovascular mortality in the Czech Republic over 1986-2006 and examined differences between population groups. We used analogous definitions for hot and cold spells that are based on quantiles of daily average temperature anomalies and do not incorporate any location-specific threshold. Epidemics of influenza/ acute respiratory infections were identified, and corresponding periods were excluded from the analysis. Both hot and cold spells are associated with significant excess cardiovascular mortality. The effects of hot spells are more direct (unlagged) and typically concentrated in a few days of a hot spell, while cold spells are associated with indirect (lagged) mortality impacts persisting after a cold spell ends. Although the mortality peak is less pronounced for cold spells, the cumulative magnitude of excess mortality is larger for cold than hot spells. Gender differences consist mainly of much larger excess mortality of females in hot spells and more lagged effects in females than males associated with cold spells. Effects of hot spells have a similar temporal pattern in all age groups but much larger magnitude in the elderly. For cold spells, by contrast, relative excess mortality is largest in the middle-aged population (25-59 yr). The results suggest that mechanisms playing the dominant role in inducing cold-related mortality differ between this age group (in which the effects are unlagged) and older age groups (significant excess mortality at lags of around $7 \mathrm{~d}$ and longer). For both high and low temperature extremes, the formulation of preventive measures (implemented by means of warning systems and biometeorological forecast alerts) should take into account the varied effects in individual population groups.
\end{abstract}

KEY WORDS: Human mortality - Cardiovascular diseases - Temperature extremes · Hot spells · Cold spells $\cdot$ Central Europe

Resale or republication not permitted without written consent of the publisher

\section{INTRODUCTION}

Links between weather and human health are extremely complex and are not yet understood in many aspects, despite renewed interest since the early 1990s (following from research into potential impacts of climate change on health; e.g. McMichael et al.
2006) and long-term knowledge of the existence of these links.

In the mid-latitudes, hot summer periods have a greater effect on human health and mortality than any other atmospheric phenomenon, especially in large cities (Gosling et al. 2009). While the 2003 heat waves in Western Europe (García-Herrera et al. 
2010) and the 2010 heat wave in Russia (Hoerling 2010) are examples of events associated with enormous heat-related mortality impacts, even 'moderate' hot spells often result in significant excess mortality (Huynen et al. 2001, Kyselý 2004). It is usually reported that the impacts are largest among (or confined to) the elderly while they are insignificant in the younger population.

Much less is understood about coldrelated mortality, which represents another important effect of weather on human health (Eurowinter Group 1997, Huynen et al. 2001, Keatinge 2002, Kyselý et al. 2009). This is partly because the links between mortality and low temperatures are less direct and more lagged, and partly because they are to some extent 'masked' by such confounding effects as outbreaks of influenza and other acute respiratory infections (which have been ignored in many studies on cold-related mortality, e.g. Donaldson et al. 2001a, Cagle \& Hubbard 2005, Christidis et al. 2010, even though their mortality effects are larger than those of low temperatures themselves).

The effects of both heat and cold are usually most pronounced in mortality due to cardiovascular diseases, upon which the present analysis concentrates. In the Czech Republic, mortality associated with heat waves (Kyselý 2004, Kyselý \& Kř́̌ž 2008) and cold spells (Kyselý et al. 2009) has been examined, but the previous studies were based on different definitions and approaches which did not allow for a comparative analysis. The main aims of the present study were (1) to compare the effects of summer hot spells and winter cold spells on cardiovascular mortality in the population of the Czech Republic, and (2) to compare the mortality effects in different age groups and genders. We made use of a nationwide database on daily mortality, which covers-with complete records-the period since 1986. This encompasses seasons with the hottest summers on record (1992, 1994, 2003) as well as several very cold winters (1986/87, 1995/96, 2005/06).

\section{DATA AND METHODS}

\subsection{Mortality data and their standardisation}

Cardiovascular diseases (CVDs; International Classification of Diseases, 9th Revision [ICD-9] codes 390-459, 1986-1993; ICD-10 codes I00-I99, 1994-
2006) represent by far the most frequent cause of death in developed countries, including the Czech Republic (located in Central Europe; population of around 10.3 million over the whole study period). We deal with CVD mortality also because previous studies have reported that increases in mortality associated with high and low temperature extremes are to a large extent due to CVD (e.g. Medina-Ramón \& Schwartz 2007). The dataset was provided by the Institute of Health Information and Statistics of the Czech Republic and covers all deaths with a CVD as the primary cause of death over 1986-2006. The percentage of death certificates that are based on autopsy is relatively large (30.2\% in 2006), which supports the reliability of the database.

Table 1 summarises mean annual numbers of deaths from CVD in individual population groups in the Czech Republic and their share in total (all causes) mortality. CVDs were the primary cause in around $55 \%$ of all deaths over 1986-2006; their share in total mortality increases with age, and it is larger in females than males in age groups $70+$ yr while the opposite holds true in the younger population.

Since time series of daily numbers of deaths are affected by long-term trends and seasonal changes, they need to be standardised. We applied an indirect standardisation that is commonly used in biometeorological and epidemiological studies: excess daily mortality is determined in each examined population group as deviations of the observed and expected (baseline) numbers of deaths (cf. Gosling et al. 2009). The estimated baseline mortality takes into account long-term changes related to improvements in medical care and the population's changing health status and age structure (Fig. 1c), as well as short-term variations due to the annual cycle (with mortality larger in winter than summer; Fig. 1b). Note that the overall CVD mortality declined over 1986-2006 in spite of almost constant popula- 

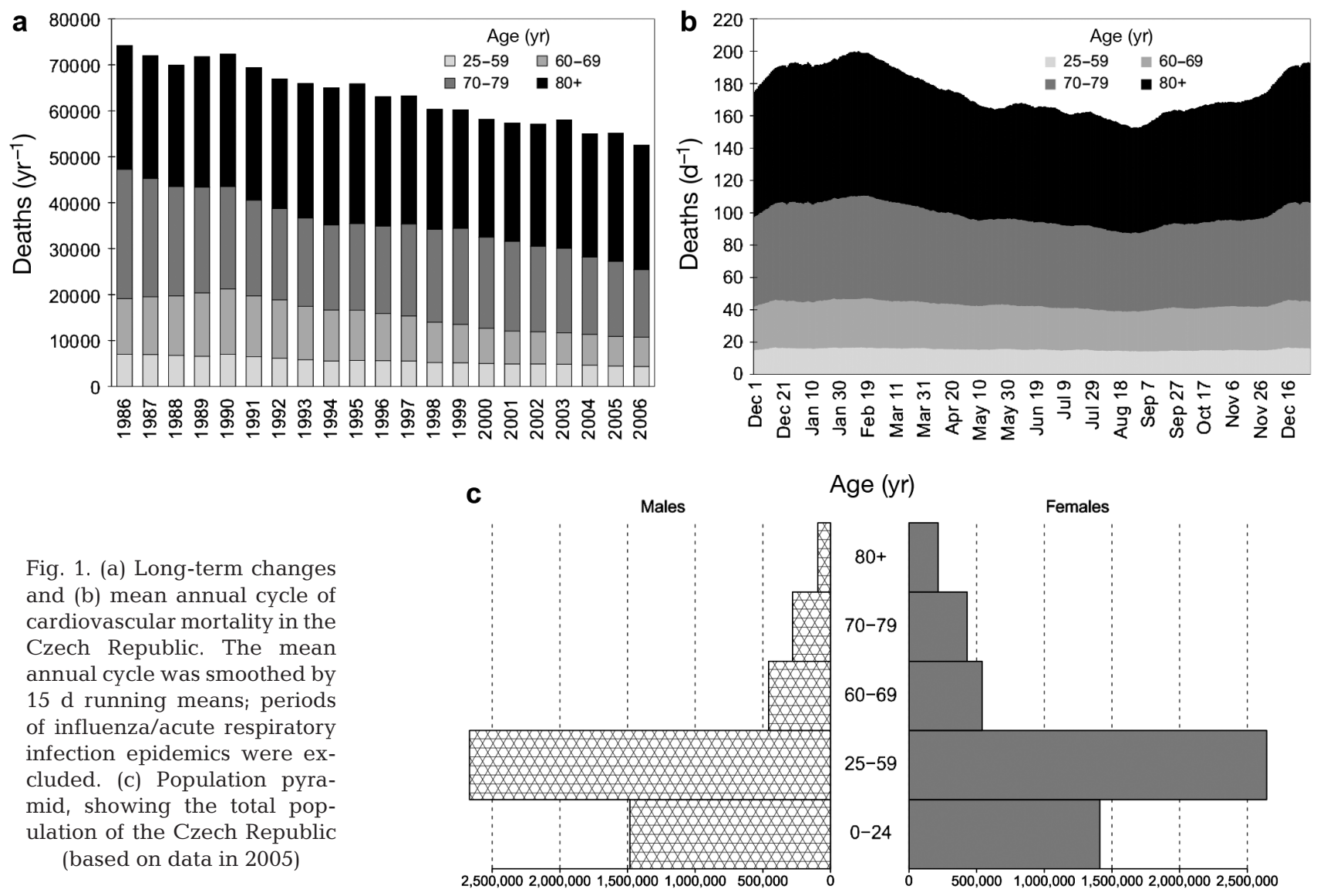

Fig. 1. (a) Long-term changes and (b) mean annual cycle of cardiovascular mortality in the Czech Republic. The mean annual cycle was smoothed by $15 \mathrm{~d}$ running means; periods of influenza/acute respiratory infection epidemics were excluded. (c) Population pyramid, showing the total population of the Czech Republic (based on data in 2005)

Age (yr) tion size (Fig. 1a). This reflects improvements in medical care as well as in general health status of the population.

Since the study includes the cold season, when the effects of influenza/acute respiratory infections on CVD mortality may be important, we identified epidemics in order to exclude corresponding periods from the data before determining the mean annual cycle of mortality. This was achieved by using a dataset on morbidity from acute respiratory infections taken from the national surveillance system, applying the standard threshold of 2000 reported ill weekly per 100000 population (Kynčl et al. 2005a). Thirteen epidemics covering altogether 399 d were identified over 1986-2006. All these occurred during December to March, with a peak in February. The lagged relationship between mortality and morbidity was found to be strongest with a $7 \mathrm{~d}$ lag of mortality after morbidity (for both genders and both total and CVD mortality; Kyselý et al. 2009), which is also in accord with a previous study that reported a lag of 7 to $10 \mathrm{~d}$ (Kynčl et al. 2005b). This lag was applied when omitting mortality data affected by epidemics from the analysis.
In mathematical terms, the expected number of deaths $M_{0}(y, d)$ for year $y(y=1986, \ldots 2006)$ and day $d(d=1, \ldots 365)$ was set in each population group according to

$$
M_{0}(y, d)=M_{0}(d) \cdot Y(y)
$$

where $M_{0}(d)$ denotes the mean daily number of deaths on day $d$ in a year, computed from the mean annual cycle smoothed by $15 \mathrm{~d}$ running means, and $Y(y)$ is a correction factor for the observed year-toyear changes in mortality, defined as the ratio of the number of deaths in year $y$ to the mean annual number of deaths during the analysed period. Correction factors for the year-to-year changes $Y(y)$ were calculated over April to November, when data are not confounded by epidemics of influenza/acute respiratory infections. The excess mortality was established for specific population groups (males, $\mathrm{M}_{i}$ and females, F) and for individual age groups as specified in Table 1 (except for age group 0-24 yr, in which CVD mortality is very low). Ratios of excess mortality relative to the expected number of deaths, expressed as a percentage above or below the baseline, are evaluated throughout the text. 
The method for estimating baseline mortality is the same as that presented by Kyselý et al. (2009). A similar standardisation procedure was also applied in e.g. Whitman et al. (1997), Guest et al. (1999), Smoyer et al. (2000) and Kyselý \& Huth (2004).

\subsection{Meteorological data}

The area of the Czech Republic is relatively small (78 $\left.866 \mathrm{~km}^{2}\right)$, which makes it possible to use average temperature series calculated from a set of meteorological stations to describe daily variations in weather. A series of average daily air temperatures representative for the Czech Republic was calculated by averaging data from 46 high-quality weather stations. The stations were selected so that no important station moves occurred during the period examined (1986-2006), and the sites fairly evenly cover the area and population under study. We do not address possible spatial variations in weather and in the relationships between weather and mortality, as the mortality data (Section 2.1) are available for the population as a whole without regional detail. The mean series for the Czech Republic is superior to that used by Kyselý \& Křiž (2008) since it yields a better spatial coverage of the area and population, particularly because it involves a much larger number of stations (46 compared to 7 ).

\subsection{Hot and cold spells}

In order to make the definitions of hot and cold spells comparable (and also easily applicable in other studies/regions), we define them both in terms of anomalies of average daily temperature from the mean annual cycle and do not incorporate any location-specific threshold. Hot (cold) spells are defined as periods of at least 2 consecutive days with anomalies of average daily temperature above the $95 \%$ quantile (below the $5 \%$ quantile). The quantiles were set from an empirical distribution of the anomalies over running $61 \mathrm{~d}$ periods centred on a given day of the year (cf. Kyselý 2008). The definition of hot spells is identical to that used by Kyselý \& Plavcová (in press). The reason for a change in the temperature parameter and the definition of hot and cold events compared to previous studies (Kyselý \& Kř́̌ž 2008, Kyselý et al. 2009) was to simplify the criteria and make them analogous for both types of events. The 95 and $5 \%$ temperature quantiles were applied by Hajat et al. (2007) to examine heat- and cold- related mortality. The use of the $95 \%$ quantile to delineate hot spells is in accord with a number of other studies (e.g. Díaz et al. 2006, Gosling et al. 2007), and the threshold of 2 d corresponds with the recommendation of Robinson (2001). We found this useful also because hot spells lasting at least $2 \mathrm{~d}$ are associated with much larger and more significant mortality impacts than are single isolated hot days, while the differences between $3 \mathrm{~d}$ and $2 \mathrm{~d}$ hot spells are minor. We use the term 'hot spell' (and not 'heat wave') in order to highlight that the definition is a relative one, based on deviations from the mean annual cycle of temperature instead of raw temperature or heat index data (to which 'heat waves' usually refer). Hot spells were analysed in summer (June-JulyAugust, JJA) and cold spells in winter (DecemberJanuary-February, DJF).

Our definitions led to reasonably large samples of hot and cold spells over the examined period: 29 hot spells and 27 cold spells were identified over 19862006, with a total duration of 83 d (hot spells) and $90 \mathrm{~d}$ (cold spells). This means that on average, hot spells cover around $4.0 \mathrm{~d}$ in summer and cold spells around $4.3 \mathrm{~d}$ in winter. The average length of individual hot (cold) spells is 2.9 (3.3) d. Interannual variability of hot and cold spells as well as mean seasonal temperatures are depicted in Fig. 2. While mean summer temperatures show a positive trend over 1986-2006, which is to some extent also reflected in characteristics of hot spells, mean winter temperatures manifest rather decadal-scale oscillations with colder winters and enhanced cold spell characteristics around the beginning, middle and end of the examined period.

\subsection{Methods}

Relative deviations of mortality from the baseline on days D-3 (3 d before the beginning of a hot/cold spell) up to D+16 (16 d after) were averaged over the identified hot/cold spells. The $20 \mathrm{~d}$ sequence encompasses several days before the beginning of a spell as well as a relatively long period after the end. We point out that mean temperature anomalies, averaged over all hot/cold spells, are already close to zero on day D+9 for both hot and cold spells (Fig. 3), but effects on mortality may persist even longer (see Section 3.1).

Statistical significance of this mean relative deviation of mortality was evaluated by comparison with the 90 and $95 \%$ confidence interval (CI) around the zero line, estimated from the 2.5, 5, 95 and $97.5 \%$ 


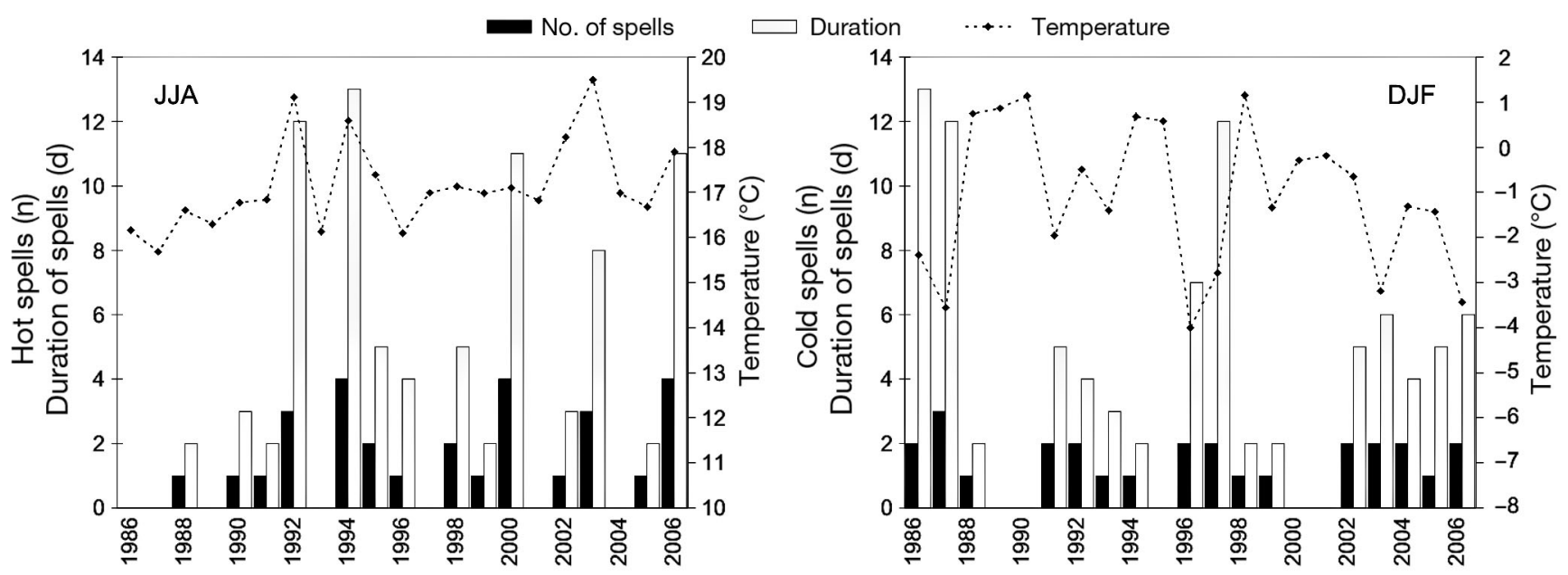

Fig. 2. Seasonal counts and durations of hot spells (left) and cold spells (right), and mean seasonal temperatures over 19862006. Winter is defined by the year it ends (e.g. winter 1986/1987 is labelled as 1987). JJA: June-July-August; DJF: DecemberJanuary-February

quantiles of a distribution calculated by the Monte Carlo method. For each examined population group, the same numbers of $20 \mathrm{~d}$ sequences ( $\mathrm{D}-3$ to $\mathrm{D}+16)$ as the counts of the hot/cold spells were randomly drawn 10000 times from the data over 1986-2006 in a given season, to estimate the corresponding quantiles. Periods in which mortality was affected by epidemics of influenza/acute respiratory infections were excluded from all calculations. This exclusion concerns only winter, in which six $20 \mathrm{~d}$ sequences around cold spells (from the total of 27 cold spells) were affected by epidemics, and the corresponding days (for 3 cold spells) or whole $20 \mathrm{~d}$ sequences (for another 3 cold spells) were omitted from the analysis.

The $95 \%$ CIs for excess mortality aggregated over hot and cold spells were calculated using the lower and upper limit factors for a Poisson-distributed variable according to Schoenberg (1983); for the number of cases $>100$, the normal approximation was used.

\section{RESULTS}

\subsection{Comparison of hot and cold spell mortality effects}

Mortality effects associated with hot and cold spells, averaged over all spells during 1986-2006, are plotted in Fig. 4 in terms of mean relative deviations from the baseline CVD mortality-separately for the whole population, males and females - and their significance is evaluated by comparison with the 90 and $95 \%$ CIs around the zero line.
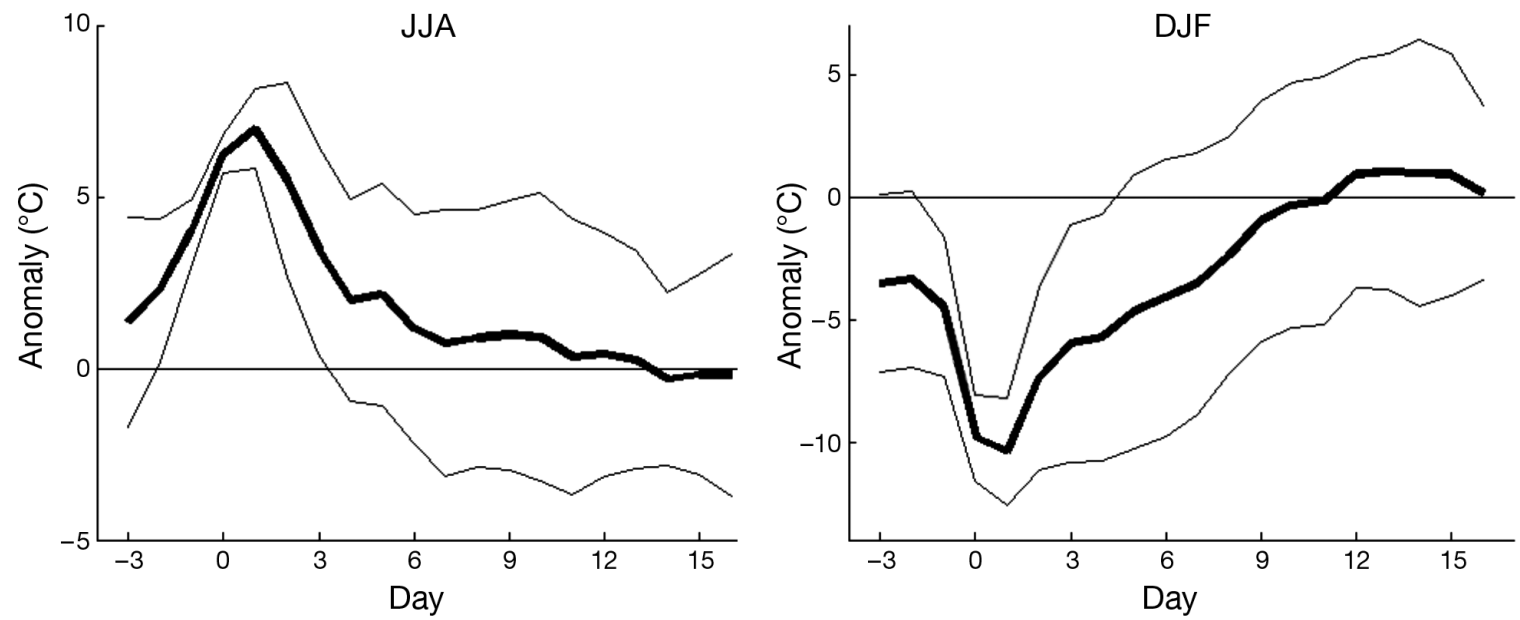

Fig. 3. Mean daily temperature anomalies spanning $3 \mathrm{~d}$ before to $16 \mathrm{~d}$ after the onset of a hot/cold spell (D-3 to D+16), averaged over hot spells (left) and cold spells (right). The upper and lower bounds show \pm 1 SD around the mean. JJA: June-July-August; DJF: December-January-February 

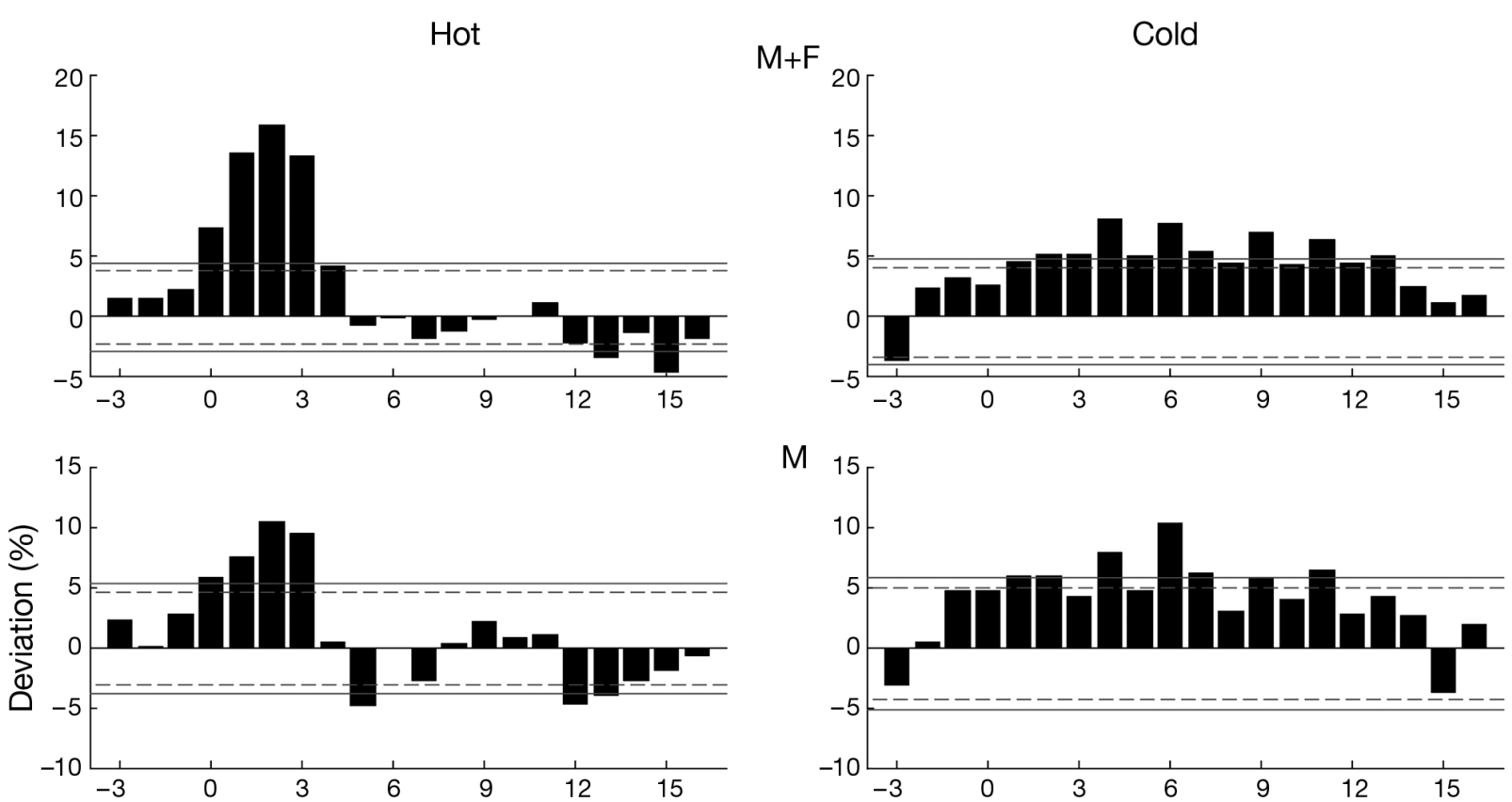

M
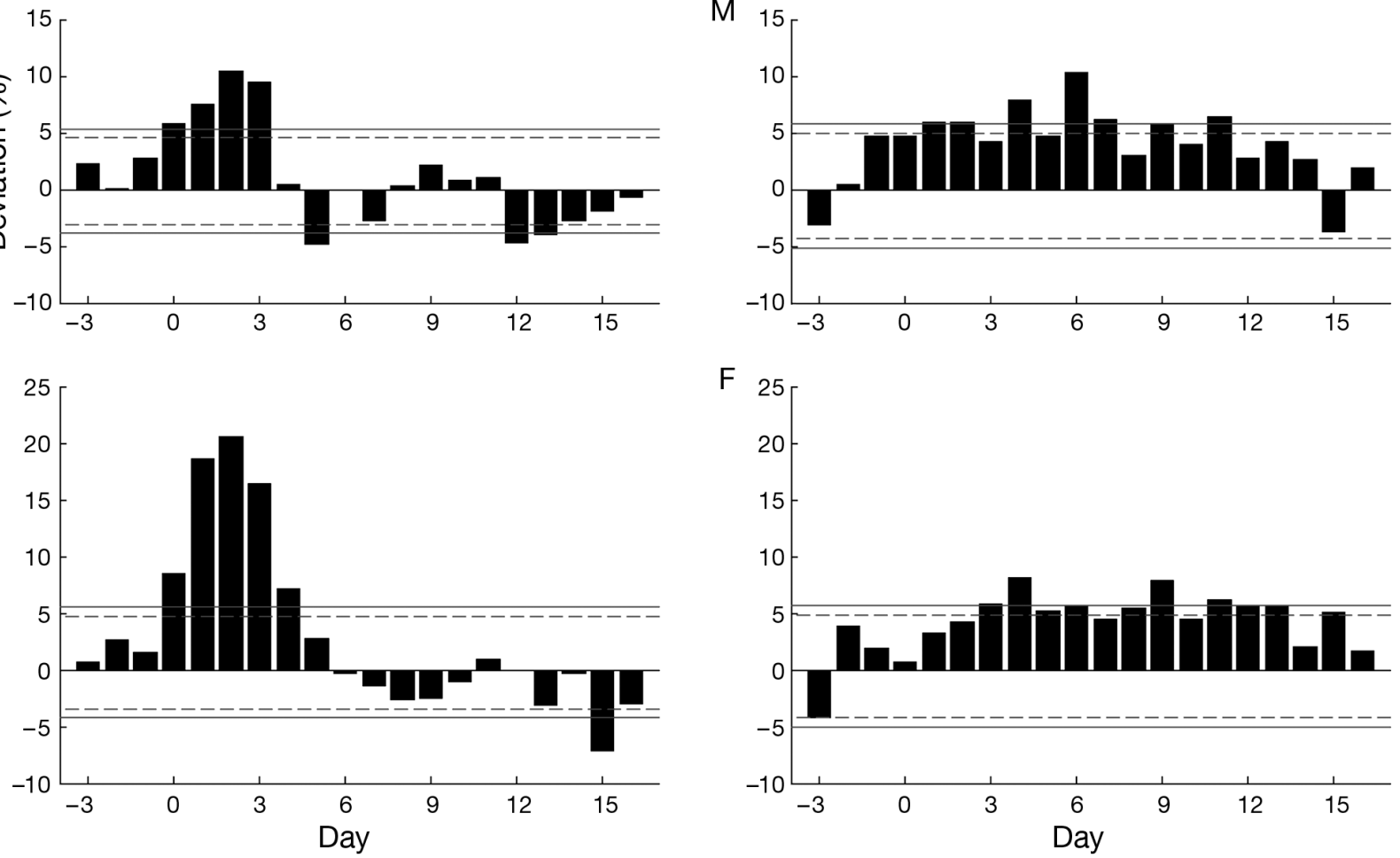

Fig. 4. Mean relative deviations of cardiovascular mortality for $20 \mathrm{~d}$ sequences spanning $3 \mathrm{~d}$ before to $16 \mathrm{~d}$ after the onset of hot spells (left) and cold spells (right) for the whole population ( $\mathrm{M}+\mathrm{F}$, top), males ( $\mathrm{M}$, middle) and females ( $\mathrm{F}$, bottom). Solid (dashed) lines denote the $2.5 \%$ and $97.5 \%$ (5\% and 95\%) quantiles of deviations obtained by the Monte Carlo method

Both hot and cold spells are linked to significant excess CVD mortality, but there is a conspicuous difference in the lag: while the effects of hot spells are direct and occur on days of hot spells (significant excess mortality on days $\mathrm{D}+0$ to $\mathrm{D}+3$ in the whole population and $\mathrm{M}$, and on days $\mathrm{D}+0$ to $\mathrm{D}+4$ in $\mathrm{F}$ ), the effects of cold spells are substantially more lagged (excess mortality lies outside the $90 \%$ CI on days $\mathrm{D}+1$ to $\mathrm{D}+13$ in the whole population, and most days between $\mathrm{D}+2$ and $\mathrm{D}+13$ are also outside the $95 \% \mathrm{CI}$ ). Note that average temperature anomalies are close to zero or are positive on days around D+10 of cold spells (Fig. 3), so the excess mortality on these days cannot be related to direct cold-stress effects.
Although the peak excess mortality is much larger for hot spells $(+15.9 \%$ on day D+2) than cold spells $(+8.0 \%$ on day $\mathrm{D}+4)$, the cumulative excess mortality is larger for cold than hot spells. If we consider the sum of excess mortality on consecutive days upon which the mean relative deviation of mortality exceeds the $95 \%$ quantile (that is, lies outside the $90 \%$ CI) as the average effect of hot and cold spells, we find average excess mortality of $54.0 \%(71.5 \%)$ relative to the daily baseline for the hot (cold) spells in the whole population. (The values were obtained by summing mean relative excess mortality on days $\mathrm{D}+0$ to $\mathrm{D}+4$ for hot spells and $\mathrm{D}+1$ to $\mathrm{D}+13$ for cold spells.) This suggests that the magnitude of the over- 
all effects on CVD mortality may be larger for cold than hot spells in spite of much smaller peak excess mortality.

Pronounced differences in the effects of hot spells are found between $\mathrm{M}$ and $\mathrm{F}$ : excess mortality is much larger in $\mathrm{F}$, exceeding $+20 \%$ on day $\mathrm{D}+2$, while it is approximately half that level in M (Fig. 4). The effects of cold spells are comparable in $\mathrm{M}$ and $\mathrm{F}$ in terms of magnitude, but the lag tends to be slightly shorter in $M$ than $F$ (excess mortality lies outside the $90 \% \mathrm{CI}$ already on days D+1 and D+2 in M, while it starts on day D+3 in F; Fig. 4).

Fig. 5 compares the effects of short hot/cold spells ( 2 to $3 \mathrm{~d}$ ) with longer spells $(4+\mathrm{d})$. For hot spells, as expected, the magnitude of the effects is larger in the latter case, and significant excess mortality persists to day $\mathrm{D}+5$, but the overall course of mortality deviations is quite similar. The pattern of excess mortality is analogous between short and longer cold spells as well, but the excess mortality is insignificant and the deviations are smaller for the latter. While this may suggest that the cumulative effects of persistent temperature anomalies are more important for hot than cold spells, the number of longer events is small for both hot (6) and cold (7) spells, and 2 out of the 7 longer cold spells were completely omitted from the analysis due to epidemics, thus making the sample even smaller. A large majority of the examined events last 2 or 3 d (i.e. most spells are very similar in their temporal extent), which also justifies the use of averages over individual spells of extreme temperature anomalies.

\subsection{Differences in individual population groups}

Fig. 6 shows that the effects of hot spells on cardiovascular mortality increase with age. They are particularly pronounced in the oldest age group $(80+\mathrm{yr})$, in which significant excess mortality occurs on all days $\mathrm{D}+0$ to $\mathrm{D}+4$. In spite of the different magnitude of the mortality effects, however, the patterns of mortality deviations in the sequence of days are quite similar in all age groups.

For cold spells in winter, the figure looks completely different than that for hot spells in summer. Rather surprisingly, the relative excess mortality is most pronounced in the middle-aged population (25-59 yr), in which the largest excess mortality is unlagged (days D+0 and D+1). Significant excess mortality is more lagged in the older age groups. This feature is particularly well-expressed in the oldest age group $(80+\mathrm{yr})$, for which significant excess mortality is found for lags $\mathrm{D}+6$ to $\mathrm{D}+11$ and
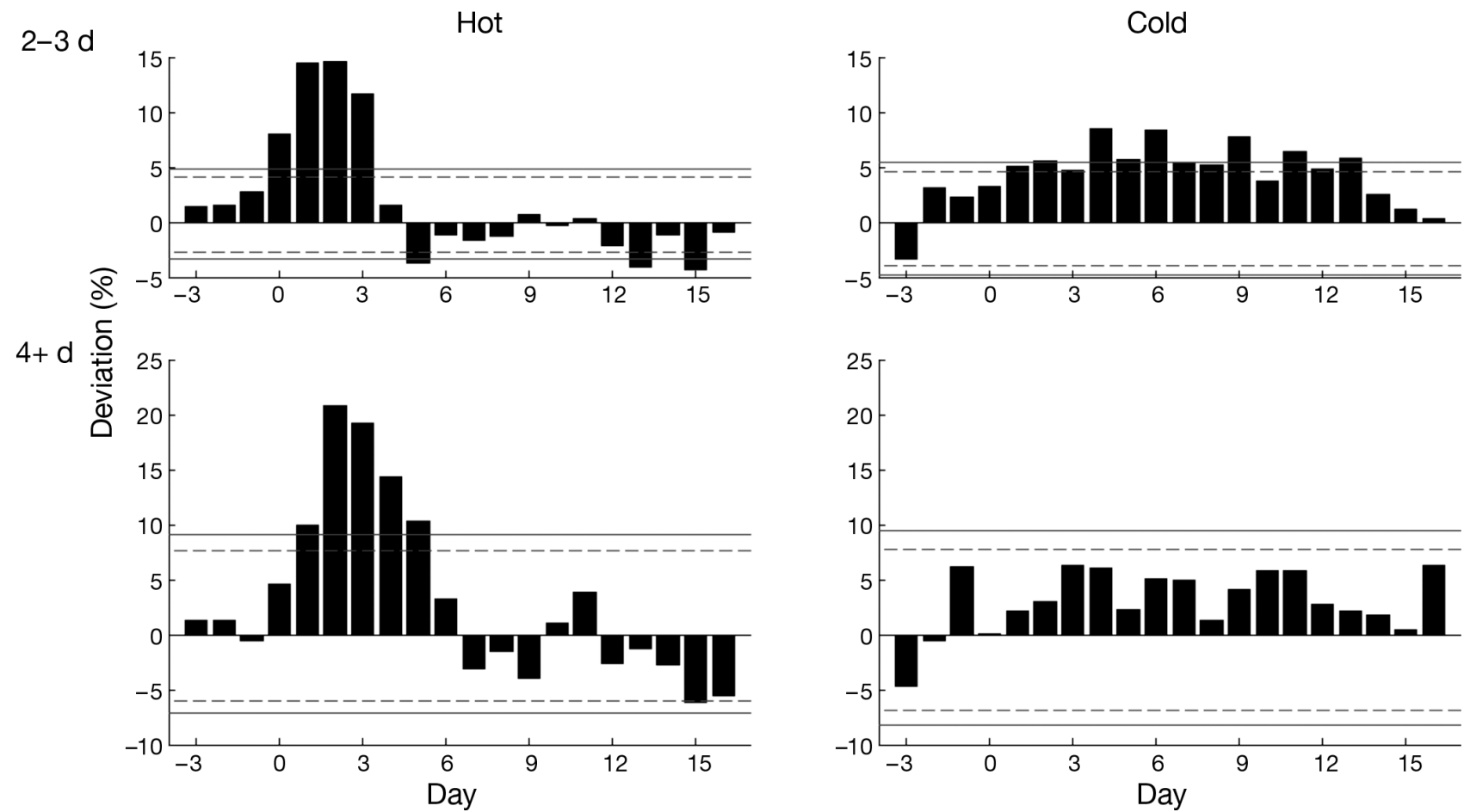

Fig. 5. Mean relative deviations of cardiovascular mortality for short spells (lasting $2-3 \mathrm{~d}$, top) and longer spells (4+d, bottom). Other details as in Fig. 4 

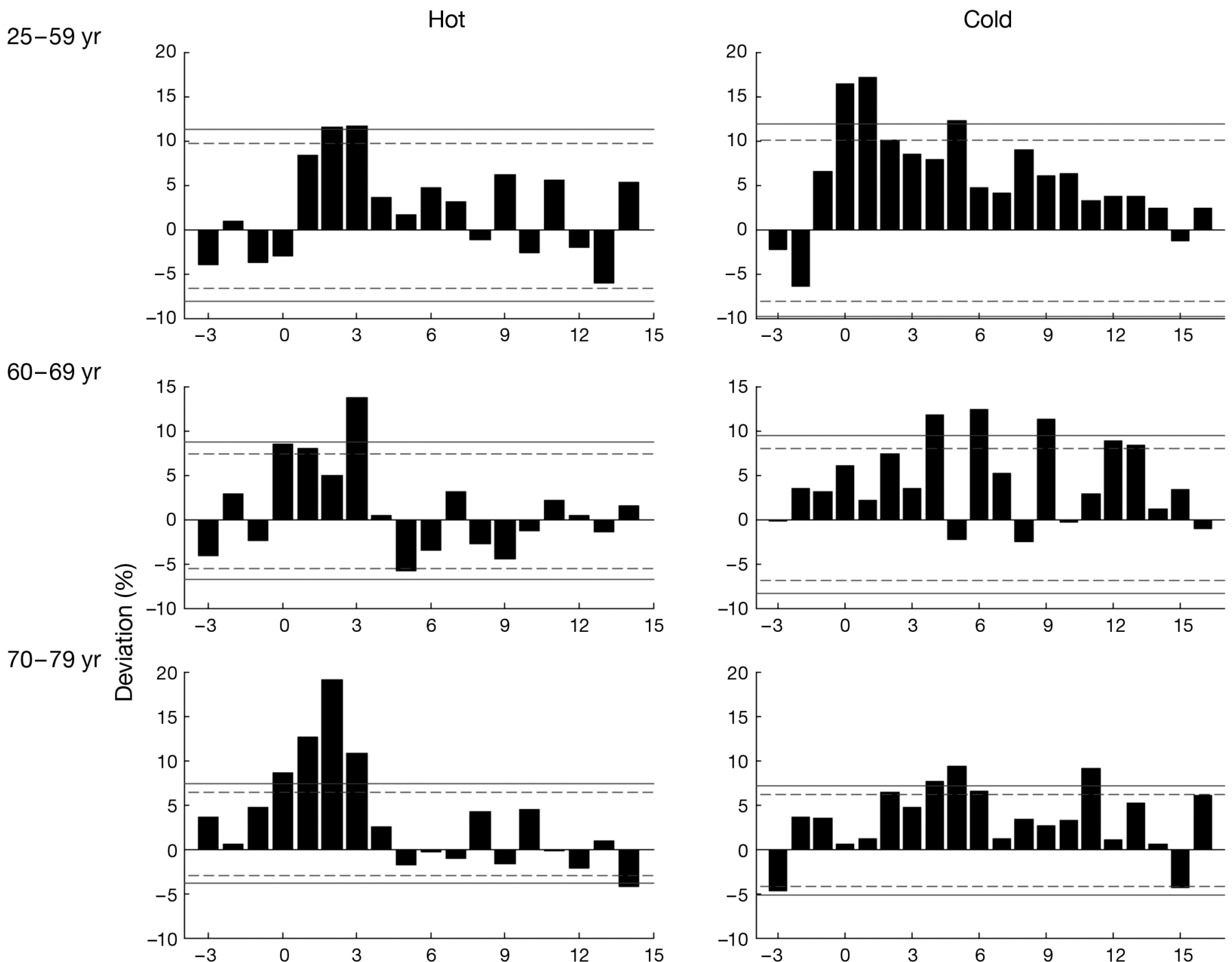

$80+y r$
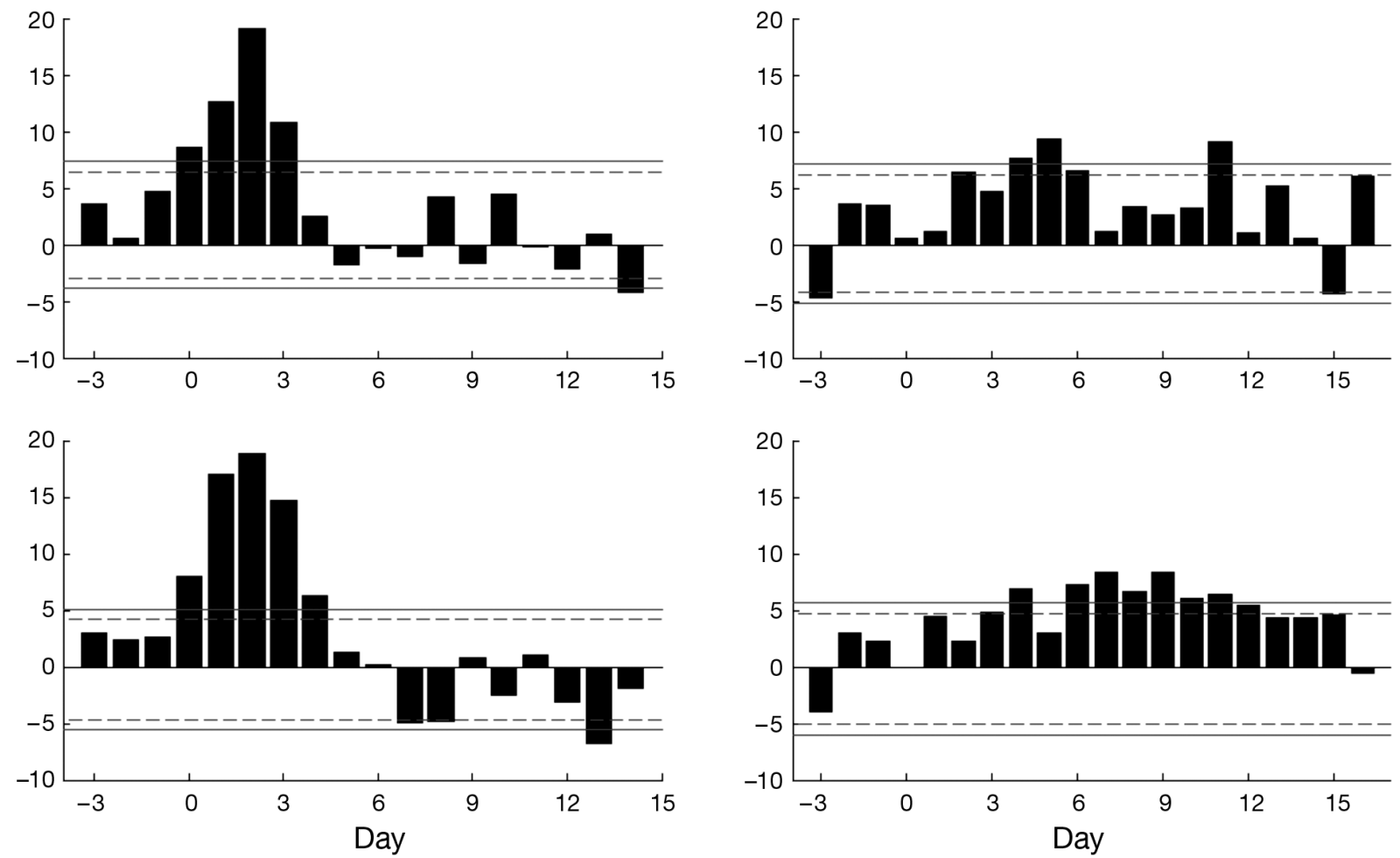

Fig. 6. Mean relative deviations of cardiovascular mortality for different age groups. Other details as in Fig. 4

not for lags which correspond to direct cold-stress effects. This obviously points to different physiological and/or behavioural mechanisms playing roles in the manifestation of CVDs among middle- aged and elderly populations, as discussed in Section 4.3.

The effects in individual population groups are further differentiated by splitting the age groups by 

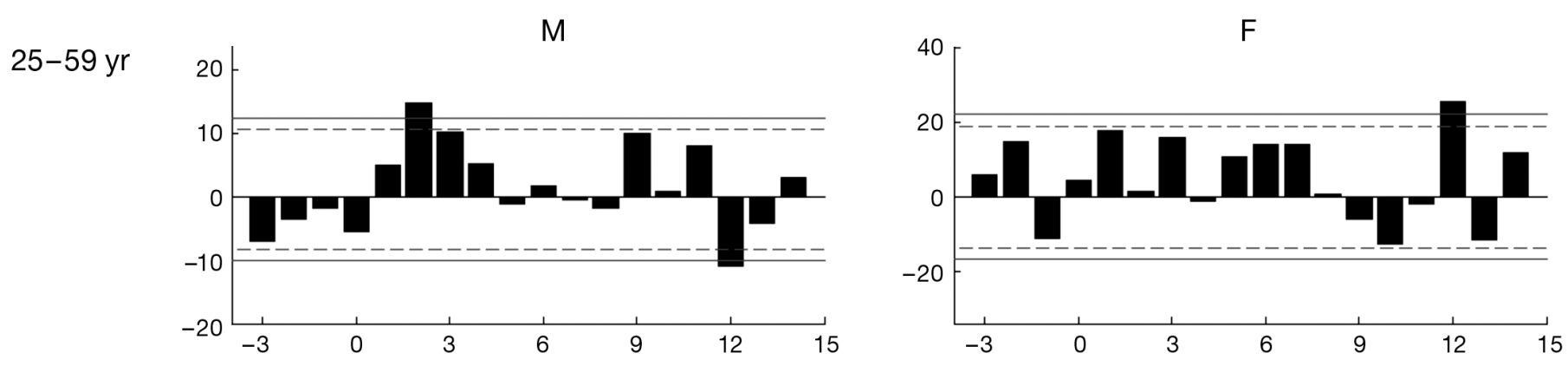

$60-69 \mathrm{yr}$
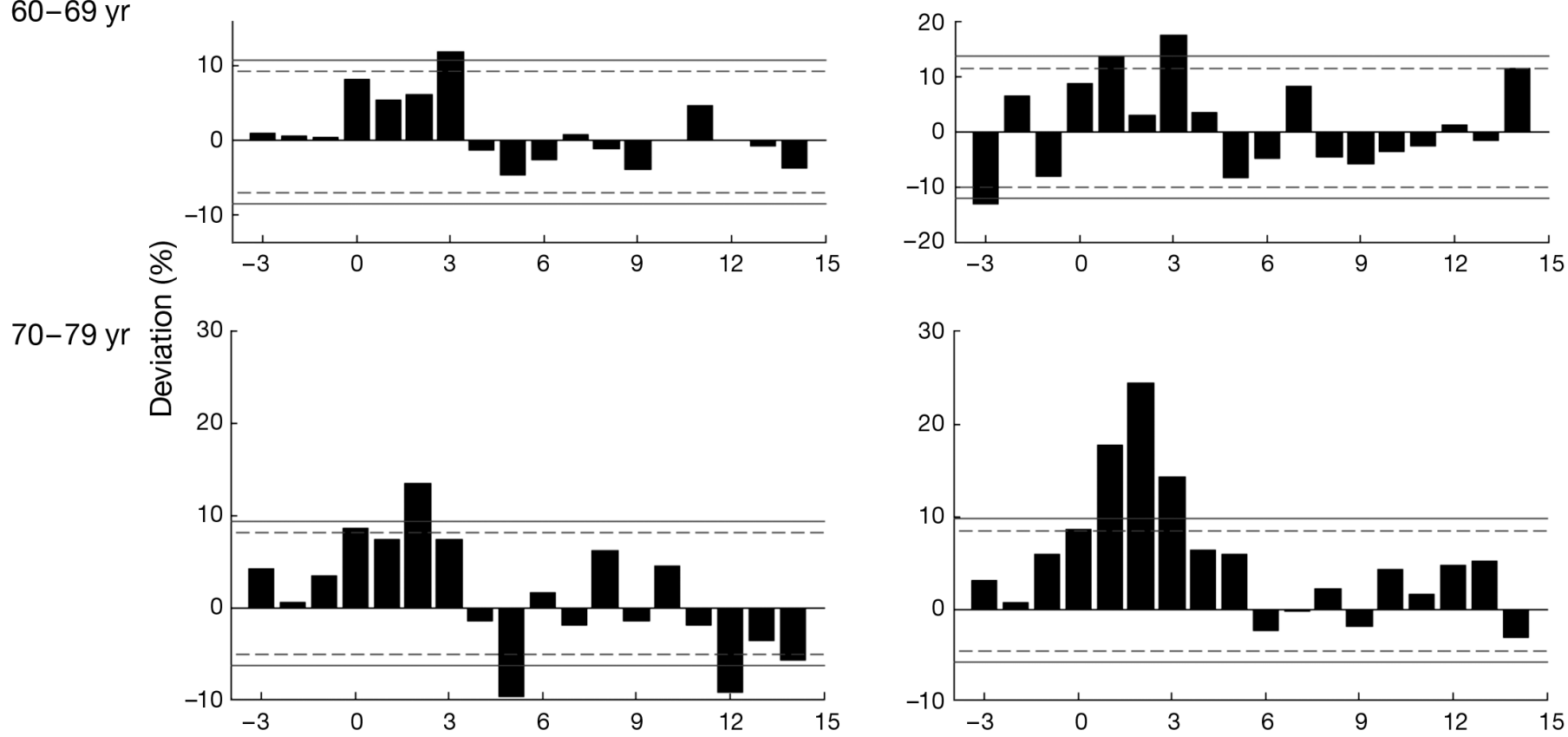

$80+y r$
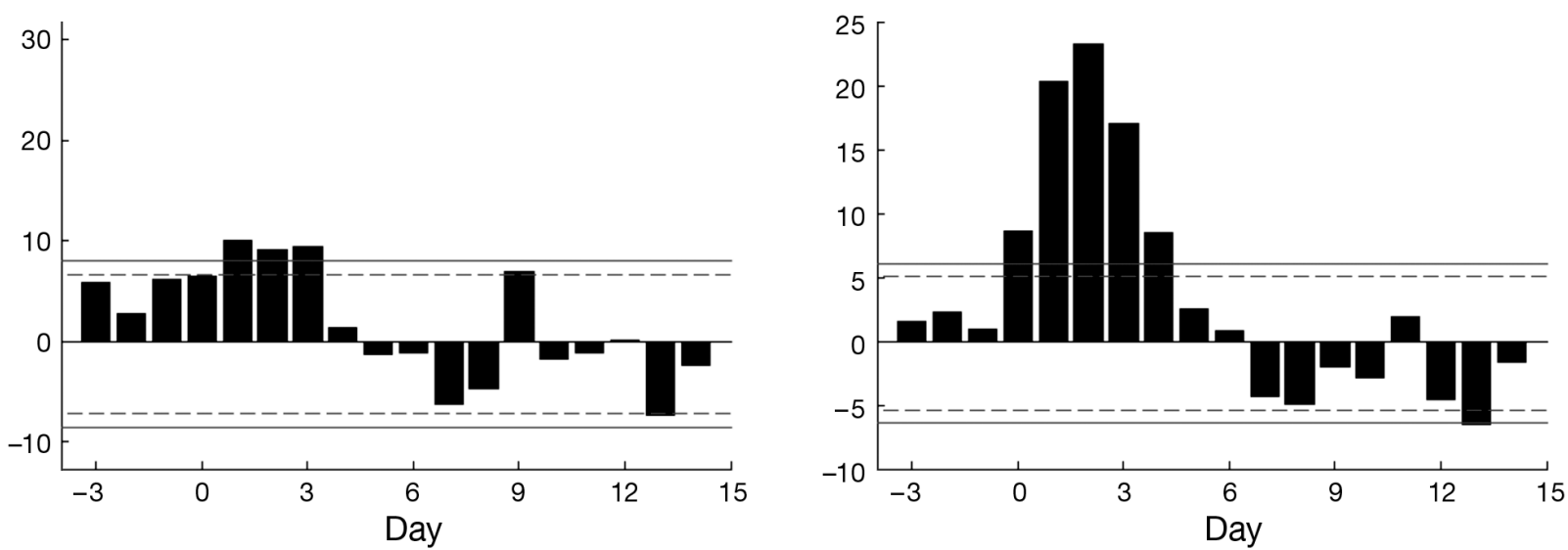

Fig. 7. Mean relative deviations of cardiovascular mortality for hot spells and different population groups. Vertical axes have been rescaled so that the width of the confidence intervals around 0 is similar in all plots. Other details as in Fig. 4

gender (Figs. 7 \& 8). Since differences in the sample size become quite pronounced in individual population groups, which results primarily in different widths of the 90 and $95 \%$ CIs for mean relative deviations of mortality, the $y$-axis was rescaled in all plots in Figs. 7 and 8 so that the CIs are visually of the same width.

Fig. 7 reveals that for hot spells, the larger magnitude of the mortality effects in the elderly is predominantly due to increasing vulnerability of females 
$25-59 \mathrm{yr}$

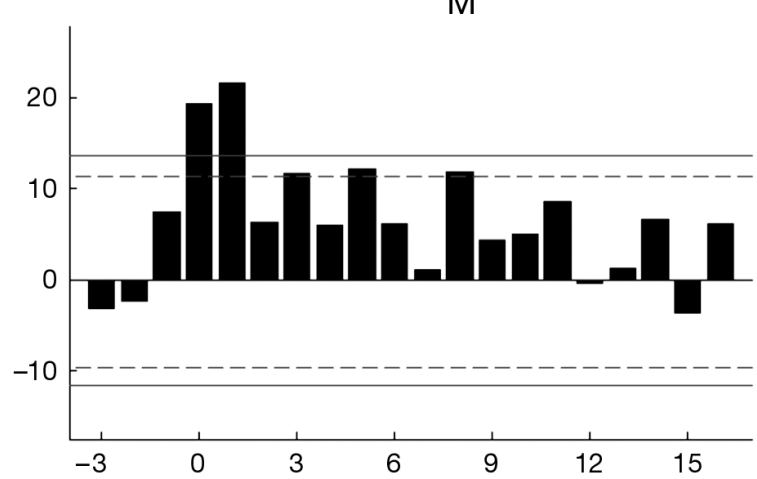

$60-69 \mathrm{yr}$

$80+\mathrm{yr}$

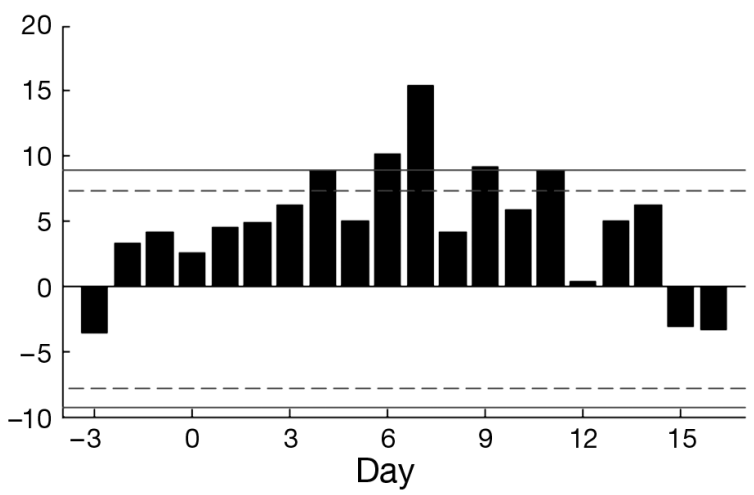

$\mathrm{F}$
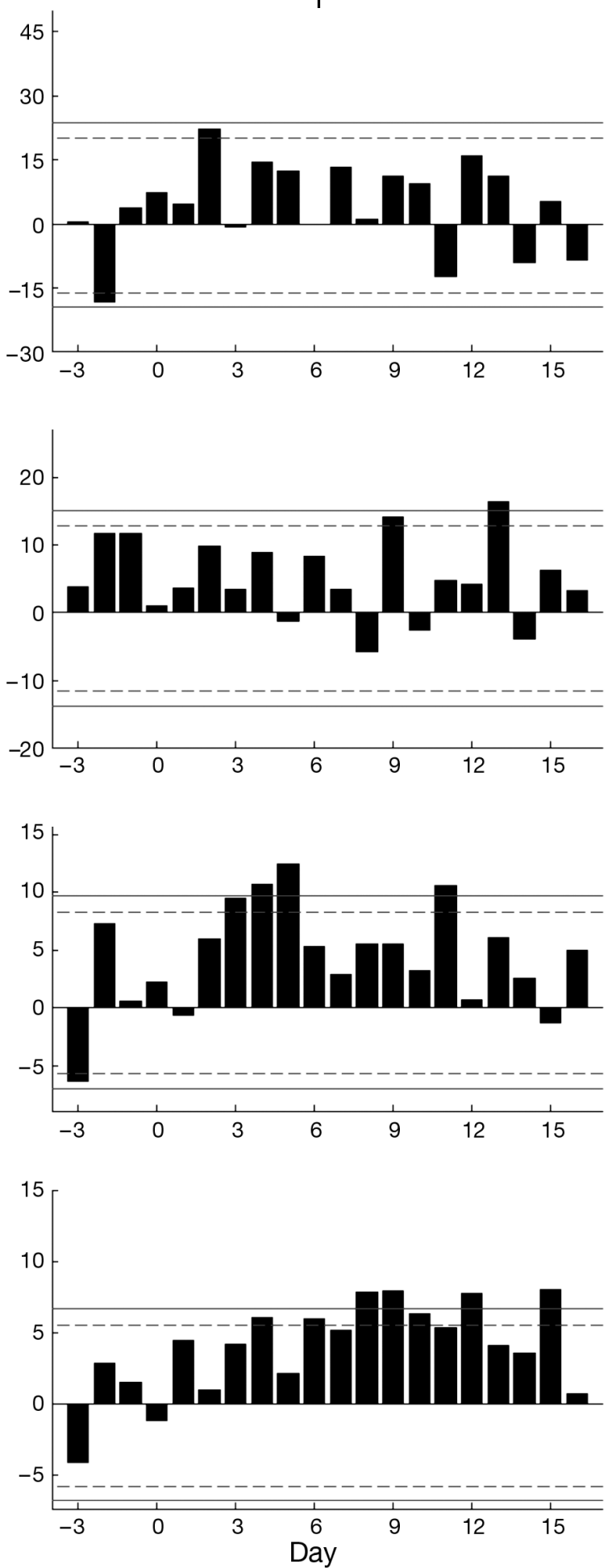

Fig. 8. Mean relative deviations of cardiovascular mortality for cold spells. Other details as in Fig. 7

with age, while the effects in males depend relatively little on age. For cold spells (Fig. 8), we found that the pronounced unlagged mortality effects in middleaged population are related to males only; the effects in females are more lagged in this population group and insignificant. For older groups, differences between males and females are relatively minor in terms of magnitude as well as lag of the excess mortality. 


\section{DISCUSSION AND CONCLUSIONS}

\subsection{Differences between hot and cold spell effects}

The study shows that both hot and cold spells are associated with significant excess cardiovascular mortality, but there are considerable differences: the effects of hot spells are more direct (unlagged) and typically concentrated on a few days of a hot spell (significant excess mortality on days $\mathrm{D}+0$ to $\mathrm{D}+4$ from the beginning of a spell), while cold spells are associated with indirect (lagged) mortality impacts that persist after the end of a cold spell (significant excess mortality on days from $\mathrm{D}+1$ to $\mathrm{D}+13)$. The shorter (longer) lag of heat-(cold-)related mortality is in agreement with findings reported by Braga et al. (2002) and Anderson \& Bell (2009), and a long lag of cold-related mortality in European cities (up to $23 \mathrm{~d}$ ) has been reported by Analitis et al. (2008). Longer lags are obviously needed to capture the effects of low temperatures on mortality, and different lag structure is essential in time series models for coldand heat-related mortality (cf. Anderson \& Bell 2009).

Although the mortality peak is less pronounced for cold spells, the cumulative magnitude of the excess mortality is larger for cold than hot spells. The average excess CVD mortality relative to the daily baseline is estimated to be $54.0 \%$ for a hot spell and $71.5 \%$ for a cold spell (both values refer to the whole population and are calculated over all spells during 1986-2006). If observed excess mortality is summed in the same way across all cold and hot spells in 1986-2006, the total estimated number of excess CVD deaths over the $21 \mathrm{yr}$ period is 3008 (95\% CI: 2523-3497) for cold spells and 2261 (95\% CI: 19842541) for hot spells. For these calculations, excess mortality on days in cold spells that were affected by epidemics was replaced using mean relative excess mortality for a given day D+x (Fig. 4), and all days $\mathrm{D}+0$ to $\mathrm{D}+4$ for hot spells $(\mathrm{D}+1$ to $\mathrm{D}+13$ for cold spells) were counted only once in case of 2 events separated by only a few days. Considering the counts of cold and hot spells over 1986-2006, this leads to an average excess number of CVD deaths associated with a single cold (hot) spell of 111 (78) in the population of the Czech Republic.

These results suggest that cold spells are events of at least similar public health concern as are hot spells (cf. similar conclusion by Analitis et al. 2008, Anderson \& Bell 2009), and much attention should be devoted to mitigating their negative effects on cardiovascular health and mortality. The finding that cold extremes may have comparably large mortality effects as do hot spells contradicts most previous studies for the US and Europe that did not incorporate lag effects or underestimated the possible lag for cold-related mortality (e.g. Barnett 2007, MedinaRamón \& Schwartz 2007). Our results support the hypothesis that some previous studies underestimated the effects of cold extremes by confining the analysis to lags that were too short.

Moreover, the overall impacts of heat-related mortality are often reduced due to a 'displacement effect' (e.g. Kyselý 2004), while cold-related mortality shows no evidence of mortality displacement (Huynen et al. 2001, Braga et al. 2002, Analitis et al. 2008). Compared to hot spells, however, possible warning systems are likely to be less efficient due to the fact that the effects are mostly indirect (lagged) and to some extent confounded by prevalence of influenza and other acute respiratory infections. Warning systems should also take into account that the effects of cold spells vary for individual population groups more than those of hot spells (as discussed in Sections 4.2 and 4.3). Our study was limited by the fact that only aggregated CVD mortality data were available, which does not allow for addressing which particular CVD diagnoses are most closely associated with hot and cold extremes.

\subsection{Differences in population groups}

\subsubsection{Males versus females}

Differences between mortality effects of hot and cold spells in males and females consist mainly of much larger excess mortality of females than males during hot spells, and more lagged effects in females than males in association with cold spells (for which the magnitude of the impacts is comparable in males and females in most age groups). Greater vulnerability to heat for females than males has been reported in a number of studies (e.g. Stafoggia et al. 2006, Hajat et al. 2007, Ishigami et al. 2008), and it is related to physiological mechanisms as well as the age and social structure of the population (e.g. a larger percentage of elderly women living alone). The physiological mechanisms include pre-existing chronic diseases, such as hypertension and diabetes (increasing the risk of CVD more markedly in women; Schenck-Gustafsson 2009, Winston et al. 2009), and adverse effects of menopause on both cardiovascular fitness and thermoregulation (altered thermoregulation, change in blood glucose control, endothelial dysfunction and vascular inflammation in 
postmenopausal women that all increase cardiovascular event risk in hot weather; Schwartz 2005, Rosano et al. 2007). People with diabetes have impaired thermoregulation and altered sweating response; consequently, reduced tolerance to heat together with increased demand on the circulatory system during heat stress may increase the risk of fatal events (Schwartz 2005, Kenny et al. 2010). Our finding that the modification of the cold effect by gender is much smaller than that of the heat effect also agrees with previous reports (e.g. Hajat et al. 2007).

\subsubsection{Age groups}

With respect to the dependence on age, the effects of hot spells have a similar temporal pattern in all age groups but much larger magnitude in the elderly. This is also consistent with most previous studies and reported underlying physical mechanisms impairing resistance to hot weather in the elderly. Thermoregulation of skin blood flow changes with age, and altered heat-induced cutaneous vasodilation may lead to cardiovascular complications (Holowatz et al. 2010). The probability of heat-related cardiovascular deaths also increases with some pre-existing chronic diseases as discussed above. The larger magnitude of the mortality impacts of hot spells in the elderly is predominantly due to the increasing vulnerability of females with age, whereas the effects in males depend relatively little on age.

For cold spells, on the contrary, relative excess mortality is largest in the middle-aged population (25-59 yr), and mechanisms playing dominant roles in inducing cold-related mortality differ between this age group (in which the effects are unlagged) and older age groups (having significant excess mortality at lags of around $7 \mathrm{~d}$ and longer; discussed in detail in Section 4.3). The large excess mortality in the middle-aged population is found primarily in males, and differences between mortality in males and females are relatively minor in older age groups. Our dataset does not allow for examining whether the differences between population groups are related to specific CVD diagnoses.

The comparison of the effects of hot and cold spells on cardiovascular mortality suggests that the relative importance of high and low temperature extremes depends on the population group (age and gender). In particular, cold extremes are relatively more harmful in the middle-aged population while warm extremes are more harmful in the elderly. For both high and low temperature extremes, preventive measures implemented by means of warning systems and biometeorological forecast alerts should take into account the varied effects in individual population groups. Adequate social services for the elderly, who comprise the most vulnerable population group during hot spells, should be taken into consideration as well.

\subsection{Possible causes and mechanisms of different cold spell effects in middle-aged and elderly populations}

Different mortality effects of cold spells in the middle-aged population (25-59 yr) and other age groups $(60+\mathrm{yr})$ is a finding that deserves more detailed investigation as to possible causes. The relative increases in mortality are larger in middle-aged males than in any other population group, and, in contrast to all other population groups, these effects are unlagged (significant excess mortality on days D+0 and D+1). This suggests that different behavioural and/or physiological mechanisms play dominant roles during cold spells in middle-aged and elderly populations. The larger mortality effects in the middle-aged population contradict most previous studies (e.g. Analitis et al. 2008), but strong cold-related effects in those younger than 65 years have already been reported, for example by Tillett et al. (1983) in the UK and O'Neill et al. (2003) in US cities.

Although indoor temperatures may also be an important factor in exposing people to cold stress in winter, the relatively direct relationship in middleaged population with a short lag after cold stress points to the effects of a shorter-term exposure to low outdoor temperatures. (We also note that housing conditions of the population with respect to protecting against cold have been of a relatively good standard over the analysed period, with the large majority of houses being equipped with central heating.) One of the reasons for much more pronounced direct effects of cold weather in the middle-aged population relates to the fact that people of productive age usually cannot adapt their daily schedules according to the weather. They cannot avoid being exposed to low ambient temperatures and large temperature contrasts between heated interiors of buildings and outdoor conditions, for example, during morning travel to work when temperatures are usually close to their daily minima. Exposure to cold induces acute physiological responses and may lead to direct cardiovascular stress due to changes in blood pressure, vasoconstriction and increase in blood viscosity and 
levels of red blood cell count, plasma cholesterol and plasma fibrinogen (Keatinge \& Donaldson 1995, Stewart et al. 2002). In addition, plasma concentrations of inflammatory markers (fibrinogen and Creactive protein, predictors of acute coronary syndromes in unstable angina pectoris) are elevated in winter (Woodhouse et al. 1994, Thompson et al. 1995). The rate of physiological response to cold may also depend on untreated cardiovascular risk factors, which probably play a larger role in the middle-aged population than the elderly (in whom medical treatment is more widespread; Andrawes et al. 2005). Untreated hypertension, accompanied by increase in arterial stiffness, blood pressure and inflammatory markers (Kampus et al. 2006), may lead to intracerebral haemorrhage (I61) in cold months (Saloheimo et al. 2009). In the Czech population, the prevalence of hypertension is high (50\% in men, 37\% in women), and it has decreased significantly only in women over the last 2 decades. About $30 \%$ of the hypertensive population are unaware of their condition (Cifkova et al. 2010) and are exposed to chronic cardiovascular stress. An ecological study comparing CVD risk factors of Czech, German and Israeli middle-aged men (Bobak et al. 1999) showed an unfavourable risk profile in Czech men that is related to high blood pressure and elevated levels of fibrinogen, triglycerides and D-dimer, a thromboembolic disease marker reflecting an activation of coagulation and predicting subsequent cardiovascular death (Morange et al. 2006).

Some underlying cardiovascular diseases (such as angina pectoris, I20) may lead to severe deterioration in health conditions after a sudden change of ambient temperature (from heated interior to very cold outdoor conditions) that may ultimately cause myocardial ischemia, acute myocardial infarction and sudden death (Lassvik \& Areskog 1979, Hong et al. 2003). The large effects in middle-aged males compared to females may be related to larger prevalence of CVD in middle-aged males (cf. CVD mortality in this age group in Table 1) and to gender-specific physiology. Reduced risk of CVD in young and middle-age women is attributable to cardioprotective effects of estrogens, which improve coronary and peripheral endothelial function, inhibit atherosclerosis development and decrease vascular resistance (Vaccarino et al. 2011). Healthy women have greater cardiac contractility and better preserved myocardial mass than do men at the same age (Mendelsohn \& Karas 2005), which may also contribute to better protection of women.

Another factor playing a role is the much larger percentage of males working outdoors and exposed to low temperatures for longer time periods. The hypothesis on the role of occupational exposure is supported by results for the city of Prague, where the percentage of people working outdoors is smaller than in other regions and the effects of cold spells on mortality are lower in the middle-aged population (Plavcová \& Kyselý 2009).

Cold weather may also contribute to CVD mortality by reducing access to a hospital or by increasing physical activity (e.g. shovelling snow; MedinaRamón \& Schwartz 2007). Overexertion in cold weather may trigger changes in blood pressure that could lead to coronary plaque rupture and subsequent coronary thrombosis (Arntz et al. 2001) as a result of a hypercoagulable state (Morange et al. 2006). Since physical activity is greater in the middleaged population, this may also contribute to the higher relative excess mortality in middle-aged males than in the elderly.

Finally, the excess deaths associated with direct exposure to cold may partly be those of homeless people who are particularly vulnerable to cold, many of whom are middle-aged males. While official statistics are not available, the numbers of homeless people were relatively small in the Czech Republic compared to western European countries at the beginning of the examined period but started to increase from the 1990s. Statistics for deaths of homeless people are incomplete and available only since 2000; over 2000-2006, they include only 6 deaths on days in which mortality may have been associated with a cold spell (i.e. days D+0 to D+13), of which 4 were due to CVD (and only 3 were males 25-59 yr of age). This suggests that deaths of homeless people do not significantly affect the overall statistics of excess CVD mortality over the examined period.

In contrast to the middle-aged population, the effects of cold spells on the elderly tend to be lagged and they persist for many days after the end of a cold spell. This suggests that cold weather may typically severely worsen cardiovascular health, which may result in death after several days. Compared to young adults, elderly people are more vulnerable to cold due to their reduced cutaneous thermal sensitivity, diminished ability to maintain core temperature and weakened cold-induced metabolic thermogenesis (Smolander 2002). Age-related increases in central arterial stiffness, coronary atherosclerosis and hypertension together with cold-induced haemoconcentration (elevated plasma fibrinogen and plasma cholesterol levels, high red blood cell count) may result in cardiovascular complications leading to death (Hess et al. 2009, Cheng \& Su 2010). Attenu- 
ated immunity resulting from winter infectious diseases may also play a role in cold-induced cardiovascular stress and, thus, the impact of cold exposure on cardiovascular health may be indirect. Compared to people of productive age, older people spend more time indoors and can customise their daily schedules to avoid direct cold exposure, which may partly explain why the mortality impacts have different temporal patterns. However, the reason for the much longer lag of cold-related mortality in the elderly is not fully understood and requires further investigation.

\subsection{Climate change effects on mortality associated with hot and cold spells}

The $21 \mathrm{yr}$ period analysed is characterised by a warming trend in summer $\left(+0.67^{\circ} \mathrm{C}\right.$ decade ${ }^{-1}$, significant at the 0.1 level, $\mathrm{p}=0.06$ ) while there is no clear trend in winter temperatures (which are dominated by decadal-scale variations; cf. Fig. 2) over the same period. If we assume, however, that both summer and winter temperatures increase in a warmer climate, as projected by climate models for Europe (Buser et al. 2010, Kjellström et al. 2011), this would enhance the characteristics of hot spells while reducing the frequency and severity of cold spells. This may result in increasing heat-related mortality but declining coldrelated mortality, and some studies have provided arguments that the overall effect would be an increase in mortality (Kalkstein \& Greene 1997, McMichael et al. 2003, Koppe 2005, Medina-Ramon \& Schwartz 2007, Doyon et al. 2008) while others argued that the declines in cold-related mortality would almost compensate for (Cheng et al. 2004) or even more than offset heat-related increases (Keatinge et al. 2000, Donaldson et al. 2001b, Davis et al. 2004).

The relationships between temperature extremes and associated mortality impacts are non-stationary, as highlighted by numerous recent studies, and observed links cannot be simply extrapolated into the future. Christidis et al. (2010) discussed the crucial role of adaptation, which in the UK prevented a significant increase in heat-related mortality and considerably enhanced a significant decrease in coldrelated mortality. On the one hand, it is likely that developed societies are able to mitigate negative impacts of hot spells to some extent, and this effect has probably contributed to declines in heat-related mortality reported in the developed world over the past few decades (e.g. Davis et al. 2002, 2003, Donaldson et al. 2003, Sheridan et al. 2009, DeCastro et al. 2011), including the population under study (Kyselý \& Plavcová in press). On the other hand, this positive tendency may in some regions already have reached its limits, both physiological and technological (Sheridan et al. 2009), and possible future warming, together with the effect of an ageing population that is becoming more vulnerable, may lead to a reversal in the favourable trends. There is also some evidence (e.g. Anderson \& Bell 2009) that persistent hot spells are associated with larger effects on mortality than are short-term spells (while no such pattern is found for cold spells, cf. Section 3.1), which may further exacerbate heat-related mortality in a warmer climate because such events would probably become more frequent and more severe.

The present study shows that cold spells have on average larger effects on mortality than hot spells, if both types of events are defined in analogous quantile-based terms and the lagged effects of cold weather are captured. In the context of climate change, substantial reductions in cold-related mortality are very likely in mid-latitudinal regions, particularly if the increasing adaptability of societies to weather is taken into account (cf. Christidis et al. 2010), and it is probable that the reductions in coldrelated mortality will be more important than possible increases in heat-related mortality. This holds true at least in developed countries that have capacities for reducing the negative effects of hot weather conditions by implementing efficient preventive and mitigation measures (including heat-watch warning systems, better standards for urban design and planning, protection of buildings against heat and cold). On the other hand, since cold-related mortality is greater in warmer than colder European regions and less in regions with larger temperature variability (Analitis et al. 2008), its importance may increase due to the 'adaptation' to milder winters and consequent changes in the behaviour of individuals and in outdoor clothing (cf. Donaldson et al. 2001a).

In any case, many questions remain open. Further research is needed towards (1) better understanding the physiological mechanisms of the links between cold weather and human health, particularly as to the differences between population groups; (2) comparative studies on the effects of hot and cold weather conditions on human health and mortality, which rarely have been carried out in a systematic way; and (3) revealing and understanding non-stationarity of the weather-human health links and the role of longterm adaptation, which may also be substantially distorted by extreme events such as the 2003 heat waves in western Europe and the 2010 heat waves in 
Russia. One should also keep in mind that climate change may alter seasonality patterns of 'baseline' mortality as well as the spread of infectious diseases (including common respiratory infections), which might also substantially influence the human health effects of cold and hot spells in a possible warmer climate.

Acknowledgements. Data were kindly provided by the Czech Hydrometeorological Institute (meteorological data) and the Institute of Health Information and Statistics of the Czech Republic (mortality data). Thanks to B. Kř́ž (National Institute of Public Health, Prague) and L. Pokorná (Institute of Atmospheric Physics, Prague) for preparing mortality datasets and identifying epidemics of acute respiratory infections. We also thank S. Vybíral (Faculty of Science, Charles University, Prague) for comments on an earlier version of the draft. Comments of 3 anonymous reviewers helped improve the original manuscript. The study was supported by the Czech Science Foundation under project P209/11/1985.

\section{LITERATURE CITED}

Analitis A, Katsouyanni K, Biggeri A, Baccini M and others (2008) Effects of cold weather on mortality: results from 15 European cities within the PHEWE project. Am J Epidemiol 168:1397-1408

Anderson BG, Bell ML (2009) Weather-related mortality: how heat, cold, and heat waves affect mortality in the United States. Epidemiology 20:205-213

Andrawes WF, Bussy C, Belmin J (2005) Prevention of cardiovascular events in elderly people. Drugs Aging 22: 859-876

> Arntz HR, Müller-Nordhorn J, Willich SN (2001) Cold Monday mornings prove dangerous: epidemiology of sudden cardiac death. Curr Opin Crit Care 7:139-144

Barnett AG (2007) Temperature and cardiovascular deaths in the US elderly: changes over time. Epidemiology 18: 369-372

Bobak M, Hense HW, Kark J, Kuch B and others (1999) An ecological study of determinants of coronary heart disease rates: a comparison of Czech, Bavarian and Israeli men. Int J Epidemiol 28:437-444

> Braga ALF, Zanobetti A, Schwartz J (2002) The effect of weather on respiratory and cardiovascular deaths in 12 US cities. Environ Health Perspect 110:859-863

- Buser CM, Kunsch HR, Schar C (2010) Bayesian multimodel projections of climate: generalization and application to ENSEMBLES results. Clim Res 44:227-241

Cagle A, Hubbard R (2005) Cold-related cardiac mortality in King County, Washington, USA 1980-2001. Ann Hum Biol 32:525-537

Cheng CS, Auld H, Li G, Klaassen JM and others (2004) An analysis of possible climate change impacts on human mortality in South Central Canada. Proc 16th Conf Biometeorol Aerobiol, American Meteorological Society, Vancouver

Cheng X, Su H (2010) Effects of climatic temperature stress on cardiovascular diseases. Eur J Intern Med 21:164-167

Christidis N, Donaldson GC, Stott PA (2010) Causes for the recent changes in cold- and heat-related mortality in
England and Wales. Clim Change 102:539-553

Cífková R, Škodová Z, Bruthans J, Holub J and others (2010) Longitudinal trends in cardiovascular mortality and blood pressure levels, prevalence, awareness, treatment, and control of hypertension in the Czech population from 1985 to 2007/2008. J Hypertens 28:2196-2203

Davis RE, Knappenberger PC, Novicoff WM, Michaels PJ (2002) Decadal changes in heat-related human mortality in the eastern United States. Clim Res 22:175-184

> Davis RE, Knappenberger PC, Novicoff WM, Michaels PJ (2003) Decadal changes in summer mortality in U.S. cities. Int J Biometeorol 47:166-175

> Davis RE, Knappenberger PC, Michaels PJ, Novicoff WM (2004) Seasonality of climate-human mortality relationships in US cities and impacts of climate change. Clim Res 26:61-76

DeCastro M, Gomez-Gesteira M, Ramos AM, Álvarez I, DeCastro P (2011) Effects of heat waves on human mortality, Galicia, Spain. Clim Res 48:333-341

> Díaz J, García-Herrera R, Trigo RM, Linares C, Valente MA, De Miguel JM, Hernández E (2006) The impact of the summer 2003 heat wave in Iberia: How should we measure it? Int J Biometeorol 50:159-166

> Donaldson GC, Rintamaki H, Näyhä S (2001a) Outdoor clothing: its relationship to geography, climate, behaviour and cold-related mortality in Europe. Int $\mathrm{J}$ Biometeorol 45:45-51

Donaldson GC, Kovats RS, Keatinge WR, McMichael A (2001b) Overview of climate change impacts on human health in the UK. Health effects of climate change in the UK. Department of Health. Available at www.dh.gov.uk/ en/Publicationsandstatistics/Publications/PublicationsPo licyAndGuidance/DH_4007935

> Donaldson GC, Keatinge WR, Näyhä S (2003) Changes in summer temperature and heat-related mortality since 1971 in North Carolina, South Finland, and Southeast England. Environ Res 91:1-7

> Doyon B, Belanger D, Gosselin P (2008) The potential impact of climate change on annual and seasonal mortality for three cities in Quebec, Canada. Int J Health Geogr 7:23 doi:10.1186/1476-072X-7-23

Eurowinter Group (1997) Cold exposure and winter mortality from ischaemic heart disease, cerebrovascular disease, respiratory disease, and all causes in warm and cold regions of Europe. Lancet 349:1341-1346

- García-Herrera R, Díaz J, Trigo RM, Luterbacher J, Fischer EM (2010) A review of the European summer heat wave of 2003. Crit Rev Environ Sci Technol 40:267-306

Gosling SN, McGregor GR, Páldy A (2007) Climate change and heat-related mortality in six cities. 1. Model construction and validation. Int $\mathrm{J}$ Biometeorol 51:525-540

Gosling SN, Lowe JA, McGregor GR, Pelling M, Malamud BD (2009) Associations between elevated atmospheric temperature and human mortality: a critical review of the literature. Clim Change 92:299-341

> Guest CS, Wilson K, Woodward AJ, Hennessy K, Kalkstein LS, Skinner C, McMichael AJ (1999) Climate and mortality in Australia: retrospective study, 1979-1990, and predicted impacts in five major cities in 2030. Clim Res 13:1-15

> Hajat S, Kovats RS, Lachowycz K (2007) Heat-related and cold-related deaths in England and Wales: Who is at risk? Occup Environ Med 64:93-100

Hess KL, Wilson TE, Sauder CL, Gao ZH, Ray CA, Monahan KD (2009) Aging affects the cardiovascular responses 
to cold stress in humans. J Appl Physiol 107:1076-1082

Hoerling M (2010) The Russian heat wave of 2010. Earth System Research Laboratory, NOAA. Available at www. esrl.noaa.gov/psd/csi/moscow2010/ (accessed 16 February 2011)

Holowatz LA, Thompson-Torgerson C, Kenney WL (2010) Aging and the control of human skin blood flow. Front Biosci 15:718-739

Hong YC, Rha JH, Lee JT, Ha EH, Kwon HJ, Kim H (2003) Ischemic stroke associated with decrease in temperature. Epidemiology 14:473-478

Huynen MM, Martens P, Schram D, Weijenberg MP, Kunst AE (2001) The impact of heat waves and cold spells on mortality rates in the Dutch population. Environ Health Perspect 109:463-470

Ishigami A, Hajat S, Kovats RS, Bisanti L, Rognoni M, Russo A, Paldy A (2008) An ecological time-series study of heat-related mortality in three European cities. Environ Health 7:5 doi:10.1186/1476-069X-7-5

Kalkstein LS, Greene JS (1997) An evaluation of climate/ mortality relationships in large U.S. cities and the possible impacts of a climate change. Environ Health Perspect 105:84-93

Kampus P, Muda P, Kals J, Ristimae T, Fischer K, Teesalu R, Zilmer M (2006) The relationship between inflammation and arterial stiffness in patients with essential hypertension. Int J Cardiol 112:46-51

> Keatinge WR (2002) Winter mortality and its causes. Int J Circumpolar Health 61:292-299

Keatinge WR, Donaldson GC (1995) Cardiovascular mortality in winter. Arctic Med Res 54:16-18

Keatinge WR, Donaldson GC, Cordioli EA, Martinelli M and others (2000) Heat related mortality in warm and cold regions of Europe: observational study. BMJ 321: 670-673

Kenny GP, Yardley J, Brown C, Sigal RJ, Jay O (2010) Heat stress in older individuals and patients with common chronic diseases. Can Med Assoc J 182:1053-1060

Kjellström E, Nikulin G, Hansson U, Strandberg G, Ullerstig A (2011) 21st century changes in the European climate: uncertainties derived from an ensemble of regional climate model simulations. Tellus Ser A Dyn Meterol Oceanogr 63:24-40

Koppe C (2005) Gesundheitsrelevante Bewertung von thermischer Belastung unter Berücksichtigung der kurzfristigen Anpassung der Bevölkerung an die lokalen Witterungsverhältnisse [Evaluation of health impacts of thermal exposure under consideration of short-term adaptation of populations to local weather]. Ber Dtsch Wetterd 226, Offenbach am Main

Kynčl J, Paget WJ, Havlíčková M, Kříž B (2005a) Harmonization of the acute respiratory infection reporting system in the Czech Republic with the European community networks. Eurosurveillance Monthly 10:5-6

Kynčl J, Procházka B, Goddard NL, Havlíčková M, Částková J, Otavová M, Krríž B (2005b) A study of excess mortality during influenza epidemics in the Czech Republic, 1982-2000. Eur J Epidemiol 20:365-371

Kyselý J (2004) Mortality and displaced mortality during heat waves in the Czech Republic. Int J Biometeorol 49: 91-97

Kyselý J (2008) Influence of the persistence of circulation patterns on warm and cold temperature anomalies in Europe: analysis over the 20th century. Global Planet Change 62:147-163
Kyselý J, Huth R (2004) Heat-related mortality in the Czech Republic examined through synoptic and 'traditional' approaches. Clim Res 25:265-274

Kyselý J, Křriž B (2008) Decreased impacts of the 2003 heat waves on mortality in the Czech Republic: an improved response? Int J Biometeorol 52:733-745

Kyselý J, Plavcová E (in press) (2011) Declining impacts of hot spells on mortality in the Czech Republic, 1986-2009: adaptation to climate change? Clim Change

Kyselý J, Pokorná L, Kynčl J, Kříž B (2009) Excess cardiovascular mortality associated with cold spells in the Czech Republic. BMC Public Health 9:19 doi:10.1186/14712458-9-19

Lassvik CT, Areskog N (1979) Angina in cold environment. Reactions to exercise. Br Heart J 42:396-401

McMichael AJ, Woodruff R, Whetton P, Hennessy K and others (2003) Human health and climate change in Oceania: risk assessment 2002. Department of Health and Ageing, Canberra

McMichael AJ, Woodruff RE, Hales S (2006) Climate change and human health: present and future risks. Lancet 367 : 859-869

> Medina-Ramón M, Schwartz J (2007) Temperature, temperature extremes, and mortality: a study of acclimatisation and effect modification in 50 US cities. Occup Environ Med 64:827-833

> Mendelsohn ME, Karas RH (2005) Molecular and cellular basis of cardiovascular gender differences. Science 308: 1583-1587

Morange PE, Bickel C, Nicaud V, Schnabel R and others (2006) Haemostatic factors and the risk of cardiovascular death in patients with coronary artery disease-the AtheroGene study. Arterioscler Thromb Vasc Biol 26: 2793-2799

O'Neill MS, Zanobetti A, Schwartz J (2003) Modifiers of the temperature and mortality association in seven US cities. Am J Epidemiol 157:1074-1082

Plavcová E, Kyselý J (2009) Comparison of the impacts of temperature extremes on mortality in Prague and other regions of the Czech Republic. In: Pribullová E, Bičárová S (eds) Sustainable development and bioclimate. Reviewed conference proceedings, Slovak Bioclimatological Society, Stará Lesná, p 213-214

Robinson PJ (2001) On the definition of a heat wave. J Appl Meteorol 40:762-775

Rosano GMC, Vitale C, Marazzi G, Volterrani M (2007) Menopause and cardiovascular disease: the evidence. Climacteric 10:19-24

Saloheimo P, Tetri S, Juvela S, Pyhtinen J, Hillbom M (2009) Seasonal variation of intracerebral haemorrhage in subjects with untreated hypertension. Acta Neurol Scand 120:59-63

- Schenck-Gustafsson K (2009) Risk factors for cardiovascular disease in women. Maturitas 63:186-190

> Schoenberg BS (1983) Calculating confidence intervals for rates and ratios. Neuroepidemiology 2:257-265

Schwartz J (2005) Who is sensitive to extremes of temperature? A case-only analysis. Epidemiology 16:67-72

Sheridan SC, Kalkstein AJ, Kalkstein LS (2009) Trends in heat-related mortality in the United States, 1975-2004. Nat Hazards 50:145-160

Smolander J (2002) Effect of cold exposure on older humans. Int J Sports Med 23:86-92

Smoyer KE, Kalkstein LS, Greene JS, Ye H (2000) The impacts of weather and pollution on human mortality in 
Birmingham, Alabama and Philadelphia, Pennsylvania. Int J Climatol 20:881-897

Stafoggia M, Forastiere F, Agostini D, Biggeri A and others (2006) Vulnerability to heat-related mortality: a multicity, population-based, case-crossover analysis. Epidemiology 17:315-323

Stewart S, McIntyre K, Capewell S, McMurray JJV (2002) Heart failure in a cold climate. J Am Coll Cardiol 39: 760-766

Thompson SG, Kienast J, Pyke SDM, Haverkate F, Vandeloo JCW (1995) Hemostatic factors and the risk of myocardial infarction or sudden death in patients with angina pectoris. N Engl J Med 332:635-641

Tillett HE, Smith JWG, Gooch CD (1983) Excess deaths attributable to influenza in England and Wales: age at death and certified cause. Int J Epidemiol 12:344-352

Editorial responsibility: Helmut Mayer,

Freiburg, Germany
Vaccarino V, Badimon L, Corti R, de Wit C and others (2011) Ischaemic heart disease in women: Are there sex differences in pathophysiology and risk factors? Cardiovasc Res 90:9-17

Whitman S, Good G, Donoghue ER, Benbow N, Shou WY, Mou SX (1997) Mortality in Chicago attributed to the July 1995 heat wave. Am J Public Health 87:1515-1518

Winston GJ, Barr RG, Carrasquillo O, Bertoni AG, Shea S (2009) Sex and racial/ethnic differences in cardiovascular disease risk factor treatment and control among individuals with diabetes in the multi-ethnic study of atherosclerosis (MESA). Diabetes Care 32:1467-1469

Woodhouse PR, Khaw K, Plummer M, Meade TW, Foley A (1994) Seasonal variations of plasma fibrinogen and factor VII activity in the elderly: winter infections and death from cardiovascular disease. Lancet 343:435-439

Submitted: March 4, 2011; Accepted: May 10, 2011

Proofs received from author(s): September 14, 2011 